\title{
Development and Evaluation of Nanoscale Sorbents for Mercury Capture from Warm Fuel Gas
}

\author{
Shakedown Testing of the Experimental System (Task 1) \\ Topical Report - 1 \\ (Revised)
}

Reporting Period

September 27, 2004 - November 30, 2004

By
Raja A. Jadhav, Ph.D.
Howard Meyer

January 2005

Work Performed under Contract No. DE-FC26-04NT42312

September 27, 2004 - March 26, 2006

For

U.S. Department of Energy, National Energy Technology Laboratory (NETL)

Ronald Brault, Project Manager

3610 Collins Ferry Road, P.O. Box 880

Morgantown, WV 26507-0880

\section{Submitted by}

Gas Technology Institute (GTI)

1700 S. Mount Prospect Road

Des Plaines, IL 60018

GTI Project Number 20162

\section{Technical Point of Contact}

$$
\text { Raja A. Jadhav, Ph.D. }
$$

Engineer, GTI

Phone: (847) 768-0807, Fax: (847) 768-0600

E-mail: raja.jadhav@gastechnology.org 


\section{DISCLAIMER}

This report was prepared as an account of work sponsored by an agency of the United States Government. Neither the United States Government nor any agency thereof, nor any of their employees, makes any warranty, expressed or implied, or assumes any legal liability or responsibility for the accuracy, completeness, or usefulness of any information, apparatus, product, or process disclosed, or represents that its use would not infringe privately owned rights. Reference herein to any specific commercial product, process, or service by trade name, trademark, manufacturer, or otherwise does not necessarily constitute or imply its endorsement, recommendation, or favoring by the United States Government or any agency thereof. The views and opinions of authors expressed herein do not necessarily state or reflect those of the United States Government or any agency thereof. 


\begin{abstract}
The Mercury Testing Experimental System available in GTI's Hot Gas Cleanup laboratory was prepared for the project. As part of the shakedown testing, the system was checked for possible gas leaks and fixed. In addition, the mass flow controller was calibrated for diluent $\mathrm{N}_{2}$ stream. A major part of the shakedown testing was the calibration of the semi-continuous mercury analyzer and the verification of the permeation rate of the mercury permeation tube. It was found that the analyzer's mercury concentration measurements were much lower than expected from the permeation tube rate calculations. Vendors of the analyzer and the permeation tube are contacted to find out the reason for this discrepancy.
\end{abstract}




\section{TABLE OF CONTENTS}

ABSTRACT

LIST OF FIGURES $\quad$ iv

EXECUTIVE SUMMARY V V

1. Experimental Methods $\quad 1$

2. Results and Discussion 2

3. Conclusion 3 


\section{LIST OF FIGURES}

Figure 1 Schematic of GTI’s experimental setup for mercury sorbent testing 1

Figure 2 Mercury concentrations obtained from PSA mercury analyzer for two channels under different configurations 


\section{EXECUTIVE SUMMARY}

Gas Technology Institute (GTI), in collaboration with Nanoscale Materials, Inc. (NMI), is developing and evaluating several nanocrystalline sorbents for capture of mercury from coalgasifier (such as IGCC) warm fuel gas. The focus of this study is on the understanding of fundamental mechanism of interaction between mercury and nanocrystalline sorbents over a range of fuel gas conditions. Detailed chemical and structural analysis of the sorbents will be carried out using an array of techniques, such as XPS, SEM, XRD, $\mathrm{N}_{2}$-adsorption, to understand the mechanism of interaction between the sorbent and mercury.

The proposed nanoscale oxides have significantly higher reactivities as compared to their bulk counterparts, which is a result of high surface area, pore volume, and nanocrystalline structure. These metal oxides/sulfides will be evaluated for their mercury-sorption potential in an experimental setup equipped with state-of-the-art analyzers. Initial screening tests will be carried out in $\mathrm{N}_{2}$ atmosphere, and two selected sorbents will be evaluated in simulated fuel gas containing $\mathrm{H}_{2}, \mathrm{H}_{2} \mathrm{~S}$, Hg and other gases. The focus will be on development of sorbents suitable for higher temperature (420-640 K) applications.

Activities in Task 1 were focused on exhaustive shakedown testing of the Mercury Testing Experimental System available in GTI's Hot Gas Cleanup laboratory. This included leak checks, mass flow controller (MFC) calibration, and mercury analyzer calibration. Gas leaks in the system were checked by monitoring the flow rate of $\mathrm{N}_{2}$ at the inlet and outlet of the reactor system. Minor leaks were observed and they were fixed. A MFC, to be used for diluent $\mathrm{N}_{2}$ stream, was calibrated to deliver $2.6 \mathrm{lpm}$ of $\mathrm{N}_{2}$. In addition, the performance of a mercury permeation tube was verified against the semi continuous PSA Mercury Analyzer. The permeation tube was calibrated by the supplier to deliver $522 \mathrm{ng} / \mathrm{min}$ of mercury at $343 \mathrm{~K}$. In 3 $\mathrm{lpm} \mathrm{N}_{2}$ stream, this corresponds to about $174 \mu \mathrm{g} / \mathrm{m}^{3}$ of $\mathrm{Hg}$ concentration. The reading of the analyzer was about $120 \mu \mathrm{g} / \mathrm{m}^{3} \mathrm{Hg}$ in $3 \mathrm{lpm} \mathrm{N}_{2}$ stream. We are currently looking into the reasons for this discrepancy. 


\section{Experimental Methods}

\section{Shakedown Testing of the Experimental System}

As part of Task 1, the mercury sorbent testing system shown in Figure 1 was checked for leaks and the mass flow controller (MFC) was calibrated. In addition, the mercury permeation tube was also calibrated using the PSA Sir Galahad-II Mercury Analyzer.

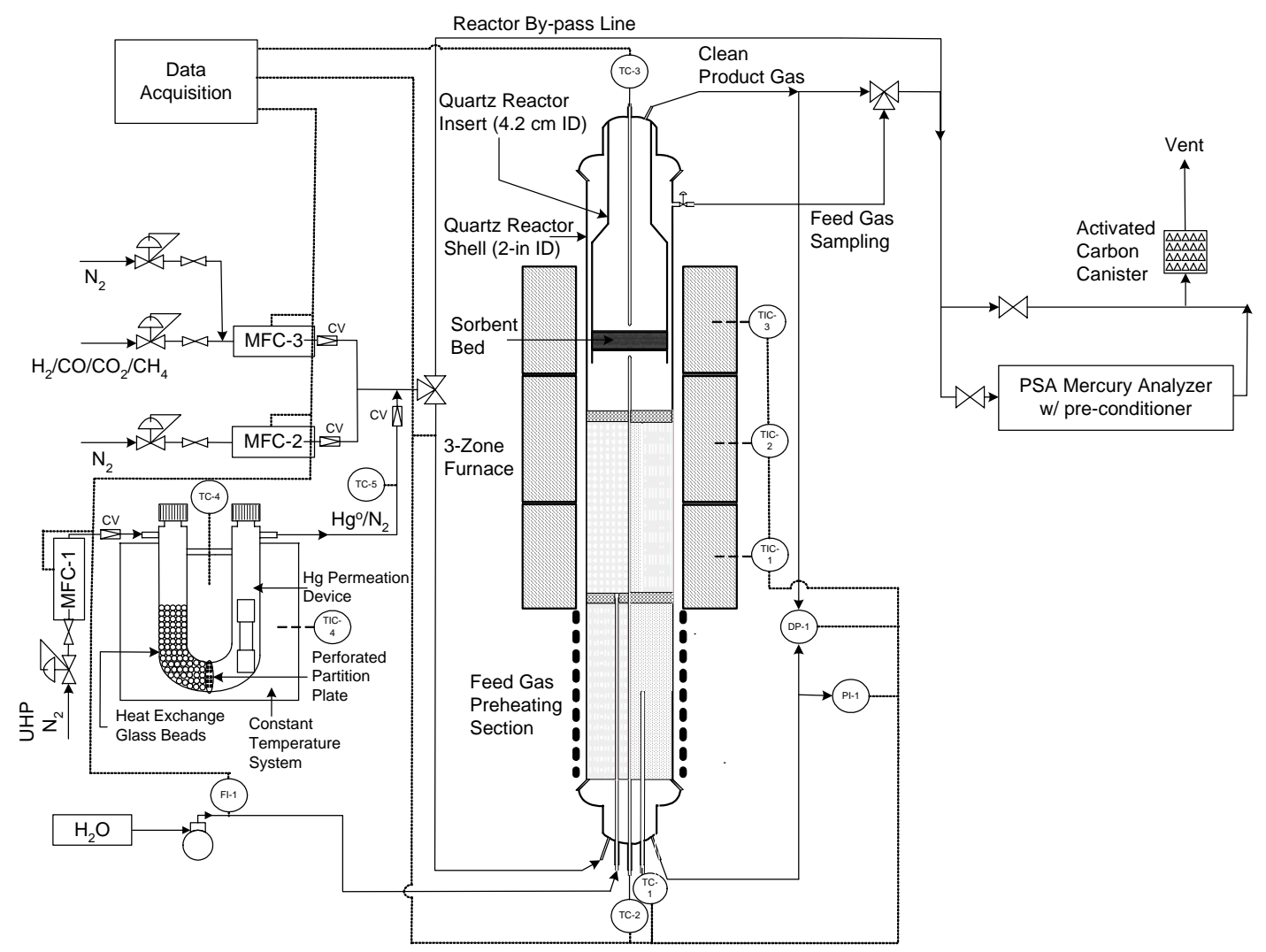

Figure 1: Schematic of GTI's experimental setup for mercury sorbent testing

The leak check was performed by verifying the flow rate of $\mathrm{N}_{2}$ at different locations in the experimental system. A flow rate of $3 \mathrm{lpm} \mathrm{N}_{2}$ was used for the leak checks and the flow rate was measured using a digital flow meter. Any drop in the flow rate would indicate a possible leak in the system.

Calibration of the MFC was performed using a soap film meter and a stopwatch.

A major effort of Task 1 was focused on calibrating and checking the performance of the mercury analyzer. A mercury permeation tube obtained from VICI Metronics as part of an earlier program was used for these tests. The permeation tube was maintained at a constant temperature of $343 \mathrm{~K}$ in a water bath with $0.4 \mathrm{lpm}$ of $\mathrm{N}_{2}$ stream flowing over the tube. The tube was calibrated to deliver $522 \mathrm{ng} / \mathrm{min}$ of $\mathrm{Hg}^{0}$ at $343 \mathrm{~K}$. Therefore, about $174 \mu \mathrm{g} / \mathrm{m}^{3}$ of $\mathrm{Hg}$ was expected when diluted in $3 \mathrm{lpm}$ of total $\mathrm{N}_{2}$ stream. As part of the testing, the mercury stream $(0.4 \mathrm{lpm})$ was either bypassed or sent through the reactor. A diluent stream of $2.6 \mathrm{lpm}$ of $\mathrm{N}_{2}$ was always sent through the reactor. 


\section{Results and Discussion}

Leak Checks: A minor leak was found in the bottom section of the quartz reactor shell. The leak was fixed by applying a lubricant and tightening the reactor cap. No other leaks were found.

MFC Calibration: The MFC used for sending diluent $\mathrm{N}_{2}$ stream to the reactor was calibrated using a soap-film meter. For the mercury sorption experiments, $0.4 \mathrm{lpm}$ of $\mathrm{Hg}$ is mixed with 2.6 lpm of the diluent $\mathrm{N}_{2}$ stream. As part of the calibration, it was found that $25 \%$ setting on the MFC delivered 2.6 lpm of $\mathrm{N}_{2}$. This setting of the MFC will be used for all the experiments to be carried out in $\mathrm{Hg} / \mathrm{N}_{2}$ stream.

Mercury Analyzer Calibration: The mercury testing system consists of Teflon ${ }^{\circledR}$ tubing and quartz reactor tube, both of which do not have any affinity for elemental mercury, even at room temperature. Therefore, the loss of mercury in the reactor system can be assumed negligible. The mercury analyzer has two separate channels to analyze both elemental and oxidized mercury. Since only elemental mercury was sent to the analyzer in this case, both the channels are expected to show similar mercury readings.

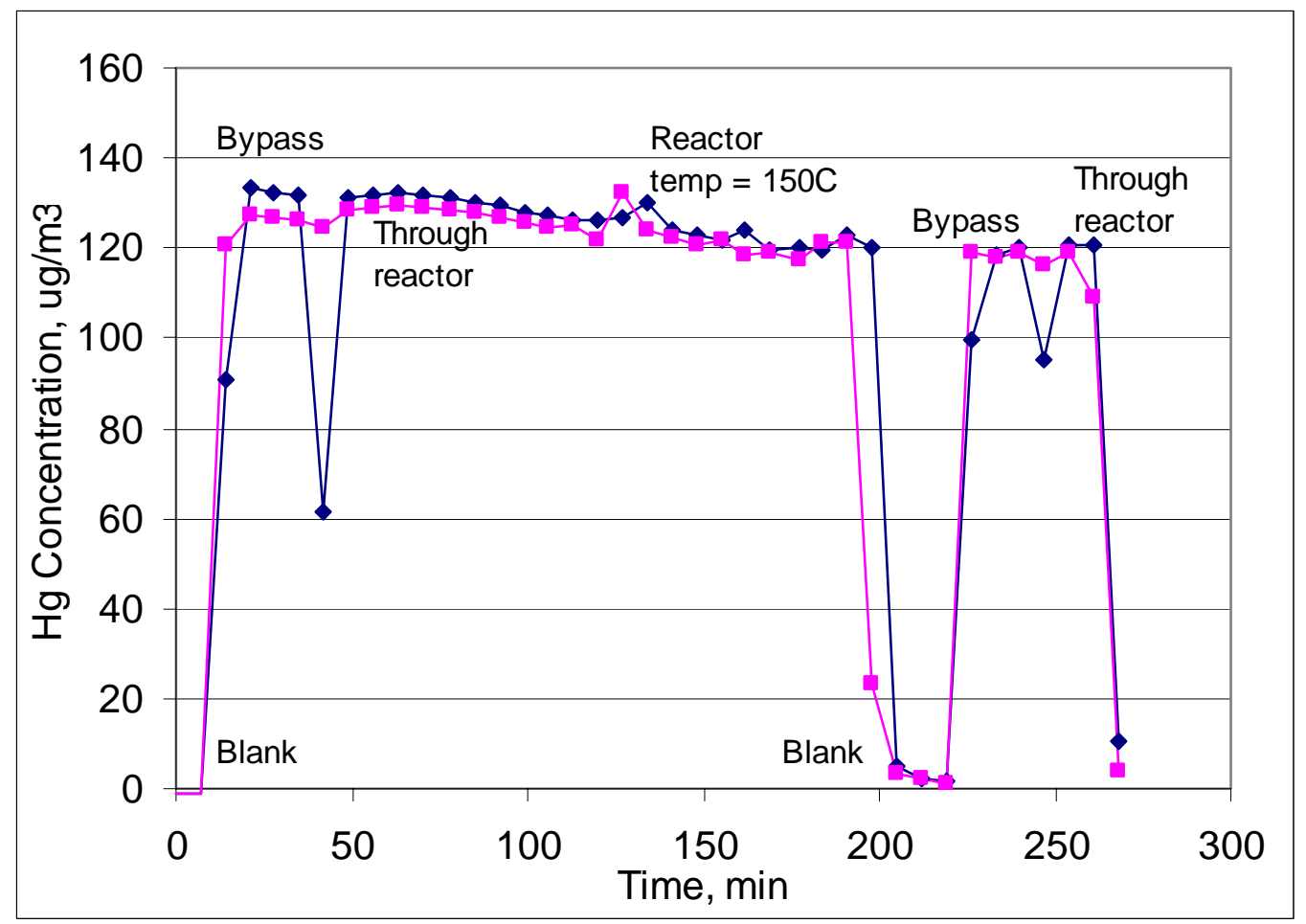

Figure 2: Mercury concentrations obtained from PSA mercury analyzer for two channels under different configurations

Figure 2 shows a plot of mercury concentration obtained in various configurations. Initially, 0.4 lpm of Hg-laden $\mathrm{N}_{2}$ stream bypassed the reactor, and was mixed and diluted with $2.6 \mathrm{lpm}$ of $\mathrm{N}_{2}$ at the reactor exit and sent to the analyzer. Bypassing the reactor eliminated any possibility of mercury loss in the reactor system. The analyzer showed nearly $130 \mu \mathrm{g} / \mathrm{m}^{3}$ of $\mathrm{Hg}$ when the 
$\mathrm{Hg} / \mathrm{N}_{2}$ stream bypassed the reactor. This reading appeared to decrease slowly with time. When the $\mathrm{Hg}$ was sent through the reactor, nearly the same reading for $\mathrm{Hg}$ concentration was observed. After one and half hours, the mercury concentration appeared to be stable around $125 \mu \mathrm{g} / \mathrm{m}^{3}$. The difference between the two $\mathrm{Hg}$ channels was also negligible.

Next, the reactor was heated to $423 \mathrm{~K}$ to determine any effect of temperature on the $\mathrm{Hg}$ concentration. As shown in the figure, the $\mathrm{Hg}$ concentration of $120 \mu \mathrm{g} / \mathrm{m}^{3}$ was obtained. After this, the Hg stream was sent to the vent to obtain a blank reading. Next, the above procedure was repeated to obtain $\mathrm{Hg}$ concentration for both the bypass and through-reactor configurations. The figure shows that for both these configurations, about $120 \mu \mathrm{g} / \mathrm{m}^{3}$ of $\mathrm{Hg}$ concentration was obtained.

Based on these studies, it can be concluded that there is no noticeable effect of the quartz reactor (as well as its temperature) on the mercury concentration in the gas stream.

It also appears that some time should be allowed to get a stable Hg reading.

The PSA analyzer shows a value of $120 \mu \mathrm{g} / \mathrm{m}^{3}$ for the permeation tube that was calibrated for $174 \mu \mathrm{g} / \mathrm{m}^{3}$. Loss of elemental mercury in the transport tubing and reactor was not possible as the entire contact surface was either Teflon ${ }^{\circledR}$ or quartz, both of which are inert towards elemental mercury. It is possible that the calibration of the permeation tube is no longer valid, being in use for more than 2 years. The manufacturer of the permeation tube will be contacted to perform a recalibration or to obtain a new permeation tube. Additionally, the possibility of verifying the calibration of the PSA mercury analyzer using PSA's Mercury Vapor Generator will also be explored.

\section{Conclusion}

The Mercury Sorbent Testing system available in GTI's Hot Gas Cleanup laboratory was found suitable for evaluating nanoscale mercury sorbents. As part of the initial shakedown testing, minor leaks observed in the system were fixed. The MFC was also calibrated and found to perform well. A detailed testing of the mercury analyzer and the permeation tube was carried out. It was found that the permeation rate of the mercury tube, as determined by the mercury analyzer, was lower than the certified value. Further testing/evaluation will be carried out to understand the reasons for this discrepancy. 